\title{
Change in the Health System Structure is a Way to Support Parents Having Children with Thalassemia: A Qualitative Study
}

\author{
Haydeh Heidari ${ }^{1,{ }^{*}}$ and Ali Ahmadi ${ }^{1}$ \\ ${ }^{1}$ Modeling in Health Research Center, Shahrekord University of Medical Sciences, Shahrekord, Iran \\ "Corresponding author: Assistant Professor, Faculty of Nursing and Midwifery, Modeling in Health Research Center, Shahrekord University of Medical Sciences, Shahrekord, \\ Iran. Email: haydehheidari@gmail.com
}

Received 2018 November 05; Revised 2019 April 29; Accepted 2019 May 17.

\begin{abstract}
Objectives: This study aimed to explore the difficulties of the health system for supporting parents having children with thalassemia.

Methods: This qualitative study was done for parents having children with thalassemia in Hajar Hospital of Shahrekord University of Medical Sciences in 2017. In this study, the approach for data collection was descriptive qualitative. Ten participants, including 5 mothers, 1 grandmother, 2 fathers, and 2 nurses interviewed in this study.

Results: Analyzing the data indicated two categories. The first category needed to change the marriage laws of couples with thalassemia containing two subcategories as follows: marriage prevention of couples with thalassemia and prevention of childbirth. The second category involved with the drug crisis, containing three subcategories as follows: the lack of drugs, inability to provide drugs, and drug complications.

Conclusions: Health authorities must take the necessary measures to provide the appropriate treatment and drugs for these patients. Also, there is a need for adequate laws and programs for couples to play a role in preventing childbirth with thalassemia.
\end{abstract}

Keywords: Health System, Parent, Thalassemia, Qualitative Study

\section{Background}

Thalassemia is a genetic disease (1). Children with thalassemia need long-term treatment such as blood transfusion and iron chelation. The families of these children seek information and support from the community (2). The prevalence of thalassemia is high in developing countries, especially in Asian and Mediterranean areas $(3,4)$. Iran has 25,000 patients with thalassemia that experience blood transfusion regularly (5). Results of a study showed that patients with thalassemia suffer from insufficient psychological health (6). Nowadays, the use of different therapeutic regimens for patients with thalassemia has increased their lifespan; therefore, these patients need to take many actions such as continual skilled training and counseling.

The healthcare team manage patient's problems, which are available at wards and as a result, they pay no attention to the patient's family and they feel that owing to routine care, there is no need to pay attention to the patient's family. In addition, owing to the fact that it is not clear who is responsible for supporting members of a family, this issue has worsened the situation; thus the family has been ignored (7). The chronic condition impacts on everyday life (8). Thalassemia is a major health problem not only for children and families but also for public health organization (9). The health care team has important role for educating the patients because good intervention helps them to manage their disease (10); Therefore, a multidisciplinary team is needed for the management of patients with thalassemia (11).

One of the basic cares is providing holistic care (12). Nurses as one of the bodies of the healthcare team have an important role to provide support to parents (13). Good health system and nurses and other personnel are essential for providing proper care (14). The health care team has a unique role in supporting parents having children with thalassemia, but the health system difficulties, such as drug shortage, have doubled the parents' problems. According to previous studies $(9,15)$, the health care team has a key role in providing proper intervention, but there is no qualitative study about parents having children with thalassemia. One study revealed that although many studies have been carried out concerning quality of life of patients with thalassemia, it is necessary to do qualitative studies in families having children with thalassemia in order to de- 
termine their needs (16).

\section{Objectives}

Then this study aimed to explore the difficulties of the health system for supporting parents having children with thalassemia.

\section{Methods}

A qualitative method was used in this research, which was done in Shahrekord in 2017. The method applied to this study is a conventional content analysis (17). Ten participants, including 5 mothers, 1 grandmother, 2 fathers, and 2 nurses participated in this study. The method for selecting participants was based on purpose. In this study, selecting the participants was continued until data saturation was obtained and this is when the interview did not add any new data to the previous ones. The inclusion criteria for participants were parents having a child with thalassemia, nurses worked at least 1-year-work experience as a nurse in the thalassemia unit, and voluntary participation in this study. The exclusion criteria were parents having specific diseases such as depression -chronic diseases in which they were under treatment-and that disease causes specific needs and the parents clearly stated this issue. In addition, the parents and nurses who were not willing to continue to participate in the research.

\subsection{Data Collection}

In this study, the main method for data collection was deep, semi-structured, face to face, and individual interviews. At first, the researcher did some initial interviews to become familiar with unpredicted and probable problems. Some of the following questions will be made in the interview: Please talk about the time when your child was inflicted with thalassemia? What were your problems after the diagnosis? The interview continued by asking explorative questions such as "Is there any other issue required to be mentioned?" The average time for the interview was 30 mins.

\subsection{Data Analysis}

Content analysis was used to classify the interview's data. These steps were taken (18): First, the interview forms were read several times to achieve an overall sense of the whole. Second, the text was divided into compacted meaning units. Third, the compacted meaning units were abstracted with codes. Fourth, the codes were classified into subcategories and categories, based on comparisons of their similarities and differences. Fifth, categories were formed as expressions of the latent content of the text. The criteria of credibility, dependability, confirmability, and transferability were used for assessing the data accuracy (18).

For determining data credibility, there was a constant involvement with the subject and data. Texts of the interviews and findings were shared with some of the participants. For the purpose of determining data dependability, we used the opinions of a blind observer as a researcher who was familiar with clinical nursing and methodology of qualitative research but was not a member of the research group, and there was no agreement on results. In order to determine the confirmability of the data, all activities were registered and a report of the research process was prepared. To determine transferability, the results were shared with 2 nurses and parents with the same situation out of the study and the results were confirmed.

\section{Results}

The characteristics of the participant are shown in Table 1. Analyzing the data indicated two categories, including a group needing to change the marriage laws of couples with thalassemia and a group involving with the drug crisis (Table 2).

\begin{tabular}{lccc}
\hline Table 1. The Characteristics of the Participants & \\
\hline Participants & Number & Age, Mean \pm SD & $\begin{array}{c}\text { Work Experience, } \\
\text { Mean } \pm \text { SD }\end{array}$ \\
\hline Mother & 5 & $33 \pm 6.4$ & - \\
Father & 2 & $44 \pm 2$ & - \\
\hline Grandmother & 1 & 50 & - \\
Children & 8 & $6 \pm 3$ & - \\
\hline Nurses & 2 & $45 \pm 3$ & $20 \pm 5$ \\
\hline
\end{tabular}

\begin{tabular}{l|l|l}
\hline \multicolumn{2}{l}{ Table 2. Main Category, Categories and Subcategories } \\
\hline $\begin{array}{l}\text { Main } \\
\text { Categories }\end{array}$ & Categories & Subcategories \\
\hline \multirow{2}{*}{$\begin{array}{l}\text { Change of the } \\
\text { health system } \\
\text { structure }\end{array}$} & $\begin{array}{l}\text { Need to change the } \\
\text { marriage laws of couples } \\
\text { with thalassemia }\end{array}$ & $\begin{array}{l}\text { Marriage prevention of } \\
\text { couples with thalassemia }\end{array}$ \\
\cline { 2 - 3 } & Drug crisis & Prevention of childbirth \\
\cline { 2 - 3 } & & Lack of drugs \\
\cline { 2 - 3 } & & Inability to provide drugs \\
\cline { 2 - 3 }
\end{tabular}

4.1. Need to Change the Marriage Laws of Couples with Thalassemia

Data analyses showed the necessity of changing the marriage laws of couples with thalassemia, which was di- 
vided into two subcategories of marriage prevention of couples with thalassemia and the prevention of childbirth. Most parents demanded a change in the law to prevent the marriage of couples. When they encountered multiple problems, they considered the existence of specific laws to be the only preventive solution. In this regard, a mother said: “...Just advise you not to let the thalassemia get married and have children. Science has now progressed. We married 28 years ago and did not test. We were not happy with the marriage of my daughter, and we did not like to marry a man with thalassemia..." [g1]. Another mother stated that: “...Now patients with thalassemia are getting married very much, they make a mistake. We also wanted not to have children. Just do not let them marry each other..." [m2].

\subsection{Drug Crisis}

The category of drug crisis was characterized by three subcategories, including the lack of drugs, inability to provide drugs, and drug complications. Most parents expressed the lack of expensive drugs for their children, especially for parents who were suffering from thalassemia. It was a major problem, particularly the lack of foreign Desferal. One of the major problems was that parents had adverse effects on the market. In this regard, a mother said “...The drug problem is that patients with thalassemia have a problem with the medicine because it is really hard to overcome the Desferal problem. We already had foreign Desferal, it was very good, but now it is expensive and we are three patients, thus we have three problems. We need a lot of money..." [m3].

Most parents expressed a major problem of their children with drug complications. They stated that Desferal in the market had adverse effects. In this regard, a father said: “...Iranian Desferal causes a lot of pain. If I inject one night, I cannot work for a few days. The injection site is swollen. The pain is severe and our basic need is Desferal." Another mother stated: "...My daughter, when she injects Desferal has trouble for a few days, especially Iranian Desferal. We are currently under heavy sanctions and there is no foreign medicine and the problem of thalassemia is multiplied..." [m5]. The nurses said that: "...Most of our patients say that they are facing a problem with Desferal in your market. Desferal has problems in Iran and your foreign Desferal is not on the market. Injection site swelling is a common difficulty..." [n2].

\section{Discussion}

Analyzing the data revealed two categories. The first category needing to change the marriage laws of couples with thalassemia containing two subcategories of marriage prevention of couples with thalassemia and promote the use of contraceptive methods, and the second category involving with the drug crisis containing three subcategories as follows: the lack of drugs, inability to provide drugs, and drug complications. There was no study in this regard, but other studies showed that these parents need support and proper intervention regarding marriage prevention of couples with thalassemia and promote the use of contraceptive methods. One study stated that thalassemia produced physical, mental, economic, and social problems for parents; therefore, reducing these difficulties needs appropriate interventions (19). Thalassemia care programs should be supplied over a long time for obtaining considerable results (20). Also, another study showed that policymakers determine a strategy such as screening for prevention programs (21). Findings of another study indicated that parents' knowledge about thalassemia and preventive measures is not enough; therefore, proper intervention in the form of programs for general health training with a focus on target society are required (22). It is obvious that the marriage of couples with thalassemia leads to the birth of a child with thalassemia. Another study stated that the screening test is the best way for preventing thalassemia, but canceling the marriage is less effective, particularly in Muslim countries (23). Researchers stated that preventive program and services were not enough for the management of patients with thalassemia (24).

The current study showed that the category of the drug crisis consisted of three subcategories, including the lack of drugs, inability to provide drugs, and drug complications. However, one study showed that parents of children with thalassemia require information about the disease and they need support and counseling (25). Researchers mentioned that awareness of parents about thalassemia was inadequate (26). It is required to provide family-based services such as giving medical information to parents, family psychological support, and financial support in order to decrease parents' stress (27). This is a qualitative study; thus the results should be cautiously generalized to all communities. However, the results of this study presented that the health system should provide comprehensive planning to support the parents having children with thalassemia. The limitations of this study are as follows: the duration of the disease, or indeed the age of the child, was not considered. The number of samples was low.

\subsection{Conclusions}

Parents have many problems with the lack of drugs, inability to provide drugs, and drug complications. Health authorities must take the necessary measures to provide 
the appropriate treatment and drug for these patients. Also, there is a need for adequate laws and programs for couples to play a role in preventing childbirth with thalassemia.

\section{Acknowledgments}

This study is the outcome of the research approved by Shahrekord University of Medical Sciences, Department of Nursing and Midwifery (No. 1940). The researchers appreciate all participants who shared their experiences with us.

\section{Footnotes}

Authors' Contribution: Haydeh Heidari: 100\%, Ali Ahmadi: $55 \%$.

Conflict of Interests: The authors have no conflict of interest.

Ethical Approval: In order to monitor ethical consideration, permission was attained from the Ethics Committee of the Shahrekord University of Medical Sciences (No. 1940).

Funding/Support: This study was conducted based on a research project sponsored by the Research Deputy of Shahrekord University of Medical Sciences (No. 1940).

Patient Consent: Written informed consent was obtained from the participants. Although we completely explained research purposes and obtained informed consent for recording their voices, they were assured about the confidentiality of information. In addition, they were allowed to leave the study whenever they wanted.

\section{References}

1. Karimzaei T, Masoudi Q, Shahrakipour M, Navidiyan A, Jamalzae AA, Zoraqi Bamri A. Knowledge, attitude and practice of carrier thalassemia marriage volunteer in prevention of major thalassemia. Glob J Health Sci. 2015;7(5):364-70. doi: 10.5539/gjhs.v7n5p364. [PubMed: 26156937]. [PubMed Central: PMC4803916].

2. Palanisamy B, Kosalram K, Gopichandran V. Dimensions of social capital of families with thalassemia in an indigenous population in Tamil Nadu, India - a qualitative study. Int J Equity Health. 2017;16(1):109. doi: 10.1186/s12939-017-0609-8. [PubMed: 28646907]. [PubMed Central: PMC5483308].

3. Maheen H, Malik F, Siddique B, Qidwai A. Assessing parental knowledge about thalassemia in a thalassemia center of Karachi, Pakistan. J Genet Couns. 2015;24(6):945-51. doi: 10.1007/s10897-015-9830-z. [PubMed: 25843562].

4. Weatherall DJ. Thalassemia as a global health problem: Recent progress toward its control in the developing countries. Ann NYAcad Sci. 2010;1202:17-23. doi: 10.1111/j.1749-6632.2010.05546.x. [PubMed: 20712767].

5. Miri-Moghaddam E, Motaharitabar E, Erfannia L, Dashipour A, Houshvar M. High school knowledge and attitudes towards thalassemia in Southeastern Iran. Int J Hematol Oncol Stem Cell Res. 2014;8(1):24-30. [PubMed: 24505548]. [PubMed Central: PMC3913153].
6. Naderi M, Hormozi MR, Ashrafi M, Emamdadi A. Evaluation of mental health and related factors among patients with beta-thalassemia major in south east of Iran. Iran J Psychiatry. 2012;7(1):47-51. [PubMed: 23056118]. [PubMed Central: PMC3395967].

7. Antikchi E, Taghavi A, Rafienia P. The relationship between personality traits, mental health and quality of life in people with thalassemia. Iran J Pediatr Hematol Oncol. 2017;7(1).

8. Prasomsuk S, Jetsrisuparp A, Ratanasiri T, Ratanasiri A. Lived experiences of mothers caring for children with thalassemia major in Thailand. J Spec Pediatr Nurs. 2007;12(1):13-23. doi: 10.1111/j.17446155.2007.00085.x. [PubMed: 17233664].

9. Oliveros O, Trachtenberg F, Haines D, Gerstenberger E, Martin M, Carson S, et al. Pain over time and its effects on life in thalassemia. Am J Hematol. 2013;88(11):939-43. doi: 10.1002/ajh.23565. [PubMed: 23918696]. [PubMed Central: PMC3872488].

10. Koutelekos J, Haliasos N. Depression and thalassemia in children adolescents and adults. Health Sci J. 2013;7(4).

11. Trachtenberg FL, Mednick L, Kwiatkowski JL, Neufeld EJ, Haines D, Pakbaz Z, et al. Beliefs about chelation among thalassemia patients. Health Qual Life Outcomes. 2012;10:148. doi: 10.1186/1477-7525-10-148. [PubMed: 23216870]. [PubMed Central: PMC3545841].

12. Senol SP, Tiftik EN, Unal S, Akdeniz A, Tasdelen B, Tunctan B. Quality of life, clinical effectiveness, and satisfaction in patients with beta thalassemia major and sickle cell anemia receiving deferasirox chelation therapy. J Basic Clin Pharm. 2016;7(2):49-59. doi: 10.4103/09760105.177706. [PubMed: 27057126]. [PubMed Central: PMC4804405].

13. Heidari H, Karimollahi M, Mehrnoush N. Evaluation of the perception of Iranian nurses towards spirituality in NICUs. Iran J Neonatol. 2016;7(2):35-9.

14. Heidari H, Hasanpour M, Fooladi M. An exploration of the viewpoints of parents and nurses on care provision in neonatal intensive care units. Iran J Neonatol. 2015;6(4):30-6.

15. Oyama Y, Yonekura Y, Fukahori H. Nurse health-related quality of life: associations with patient and ward characteristics in Japanese general acute care wards. J Nurs Manag. 2015;23(6):775-83. doi 10.1111/jonm.12207. [PubMed: 24443906].

16. Majid S, Abidi M. Quality of life and coping styles of care-givers of patients Suffering from thalassemia major. Int J Med Pharm Sci. 2013;3(10):41-8.

17. Hsieh HF, Shannon SE. Three approaches to qualitative content analysis. Qual Health Res. 2005;15(9):1277-88. doi: 10.1177/1049732305276687. [PubMed: 16204405].

18. Elo S, Kyngas $\mathrm{H}$. The qualitative content analysis process. J Adv Nurs. 2008;62(1):107-15. doi: 10.1111/j.1365-2648.2007.04569.x. [PubMed: 18352969].

19. Arbabisarjou A, Karimzaei T, Jamalzaei A. The perception of biological experience in patients with major thalassemia: A qualitative research. Glob J Health Sci. 2014;7(1):79-87. doi: 10.5539/gjhs.v7n1p79. [PubMed: 25560333]. [PubMed Central: PMC4796504].

20. Rafii Z, Ahmadi F, Nourbakhsh SM, Hajizadeh E. The effects of an orientation program on quality of life of patients with thalassemia: A quasi-experimental study. J Caring Sci. 2016;5(3):2239. doi: 10.15171/jcs.2016.024. [PubMed: 27752488]. [PubMed Central: PMC5045956]

21. Li B, Zhang XZ, Yin AH, Zhao QG, Wu L, Ma YZ, et al. High prevalence of thalassemia in migrant populations in Guangdong Province, China. BMC Public Health. 2014;14:905. doi: 10.1186/1471-2458-14-905. [PubMed: 25183384]. [PubMed Central: PMC4161880].

22. Ishaq F, Abid H, Kokab F, Akhtar A, Mahmood S. Awareness among parents of beta-thalassemia major patients, regarding prenatal diagnosis and premarital screening. J Coll Physicians Surg Pak. 2012;22(4):21821. [PubMed: 22482376]. 
23. Waheed F, Fisher C, Awofeso A, Stanley D. Carrier screening for betathalassemia in the Maldives: Perceptions of parents of affected children who did not take part in screening and its consequences. J Community Genet. 2016;7(3):243-53. doi: 10.1007/s12687-016-0273-5. [PubMed: 27393346]. [PubMed Central: PMC4960032].

24. Adly AA, Ebeid FS. Cultural preferences and limited public resources influence the spectrum of thalassemia in Egypt. J Pediatr Hematol Oncol. 2015;37(4):281-4. doi: 10.1097/MPH.0000000000000327. [PubMed: 25811748]

25. Inamdar S, Inamdar M, Gangrade A. Stress level among caregivers of thalassemia patients. Community Med. 2015;6(4):579-82.

26. Goyal J, Hpapani P, Gagiya H. Awareness among parents of children with thalassemia major from Western India. Int J Med Sci Public Health. 2015;4(10):1356-9. doi:10.5455/ijmsph.2015.17042015279.

27. Kuo HT, Peng CT, Tsai MY. Pilot study on parental stress and behavioral adjustment to the thalassemia major disease process in children undergoing iron-chelation in western Taiwan. Hemoglobin. 2006;30(2):301-9. doi: 10.1080/03630260600642658. [PubMed: $16798655]$ 